\title{
Repair of tetralogy of Fallot after the regression of multiple rhabdomyomas in a patient with tuberous sclerosis
}

\author{
Won Kyoung Jhang, MD, ${ }^{\mathrm{a}}$ Hee-Suk Jung, MD, ${ }^{\mathrm{a}} \mathrm{Jae}-\mathrm{Kon} \mathrm{Ko}, \mathrm{MD},{ }^{\mathrm{b}}$ and Tae-Jin Yun, MD, PhD, \\ Seoul, Republic of Korea
}

Rhabdomyoma is reportedly the most common type of cardiac tumor in fetuses and children. We report a case of multiple cardiac rhabdomyomas associated with tuberous sclerosis and detected on fetal echocardiography in conjunction with tetralogy of Fallot (TOF). The TOF was palliated with a shunt and repaired after the rhabdomyomas had regressed.

\section{CLINICAL SUMMARY}

A male infant was born at 37 weeks' gestation and $2380 \mathrm{~g}$ birth weight. TOF and multiple cardiac tumors had been diagnosed on fetal echocardiography. Postnatal echocardiography confirmed the prenatal diagnosis: overriding of the aorta, small pulmonary valvular annulus, severe infundibular and valvular pulmonary stenosis, perimembranous ventricular septal defect, smallish branch pulmonary arteries, sizable patent foramen ovale with left-to-right shunt, and multiple echogenic cardiac masses. The largest tumor $(22 \times 29$ $\mathrm{mm}$ ) from the interventricular septum occupied almost entire left ventricular (LV) cavity (Figure 1, $A$ ), but LV inflow and outflow obstruction could not be assessed accurately. Smaller cardiac masses were located at the tricuspid valve, interatrial septum, and LV free wall. Well-known association of multiple cardiac masses with tuberous sclerosis prompted us to conduct brain magnetic resonance imaging and abdominal ultrasonography, which revealed the pathognomonic features of tuberous sclerosis: multiple cortical tubers, subependymal nodules and retinal hamartoma on brain magnetic resonance imaging (Figure 2), and multiple cysts in both kidneys on abdominal ultrasonography. Deletion of exon 10-46 of TSC2 gene mutation was also detected by a genetic test. Because the branch pulmonary arteries were small (McGoon ratio 1.1) and the patient showed progressive cyanosis from severe infundibular stenosis, a right modified Blalock-Taussig shunt with a $3.5 \mathrm{~mm}$-polytetrafluoroethylene vascular graft was placed on postnatal day 15 .

\footnotetext{
From the Divisions of Pediatric Cardiac Surgery ${ }^{\mathrm{a}}$ and Pediatric Cardiology, ${ }^{\mathrm{b}}$ Asan Medical Center, College of Medicine, University of Ulsan, Seoul, Republic of Korea.

Disclosures: None.

Received for publication May 11, 2009; accepted for publication Sept 8, 2009; available ahead of print Nov 4, 2009.

Address for reprints: Tae-Jin Yun, MD, PhD, Division of Pediatric Cardiac Surgery, Asan Medical Center, College of Medicine, University of Ulsan, 388-1 Poongnap-Dong, Songpa-gu, Seoul, Republic of Korea, 138-736 (E-mail: tjyun@ amc.seoul.kr).

J Thorac Cardiovasc Surg 2010;139:e135-6

0022-5223/\$36.00

Copyright (c) 2010 by The American Association for Thoracic Surgery

doi:10.1016/j.jtcvs.2009.09.021
}

Postoperative course was uneventful, except that antiepileptic drugs began to be used for infantile spasm at postoperative 5 months. During the follow-up period, cardiac tumors slowly decreased in size, and they had completely disappeared by the age of 18 months (Figure $1, B$ ). When the baby reached 2 years of age, he underwent total correction of TOF with preservation of the pulmonary valve annulus. No intracardiac masses were found on direct inspection of the operative field. Postoperative echocardiography showed no residual intracardiac shunt, with minimal right ventricular outflow obstruction. The patient has been
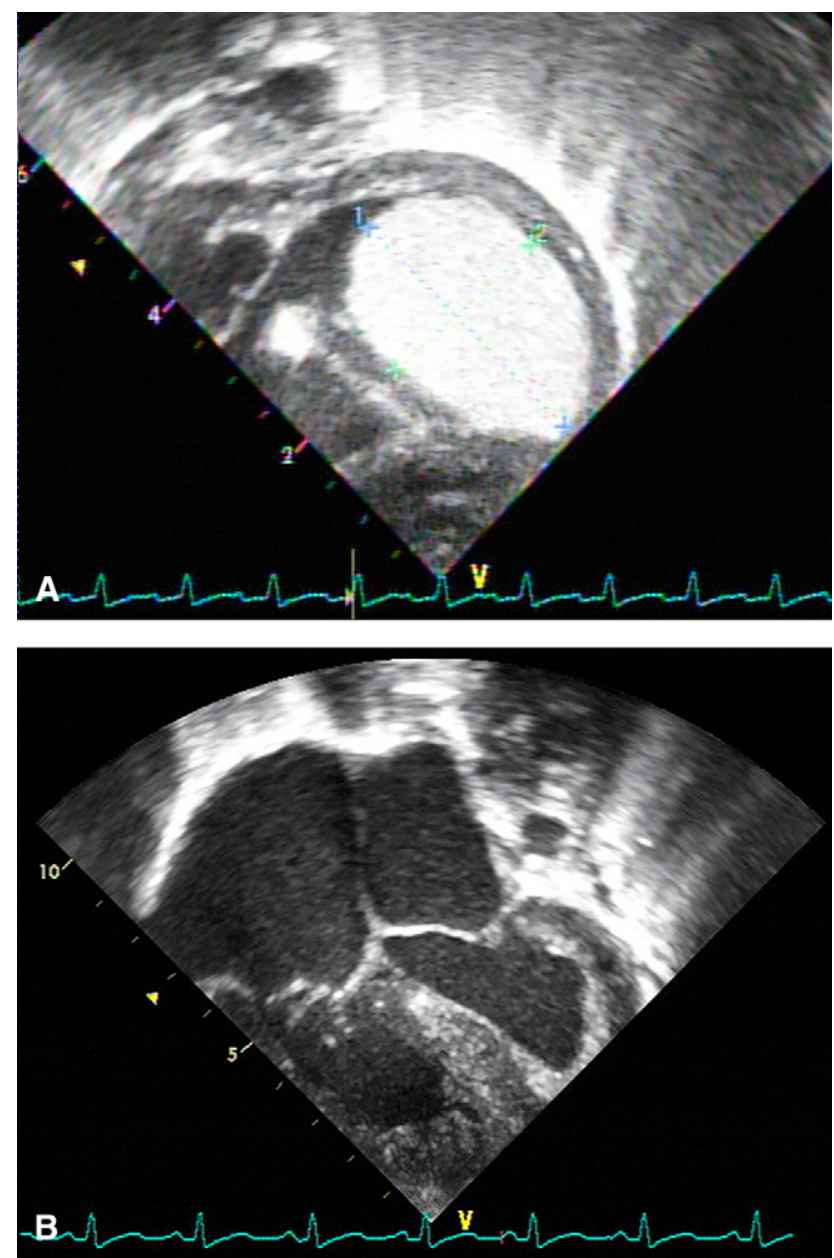

FIGURE 1. Serial echocardiography. Initial tumors occupying nearly entire left ventricular cavity at 10 days after birth (A) had disappeared completely by age 18 months (B). 

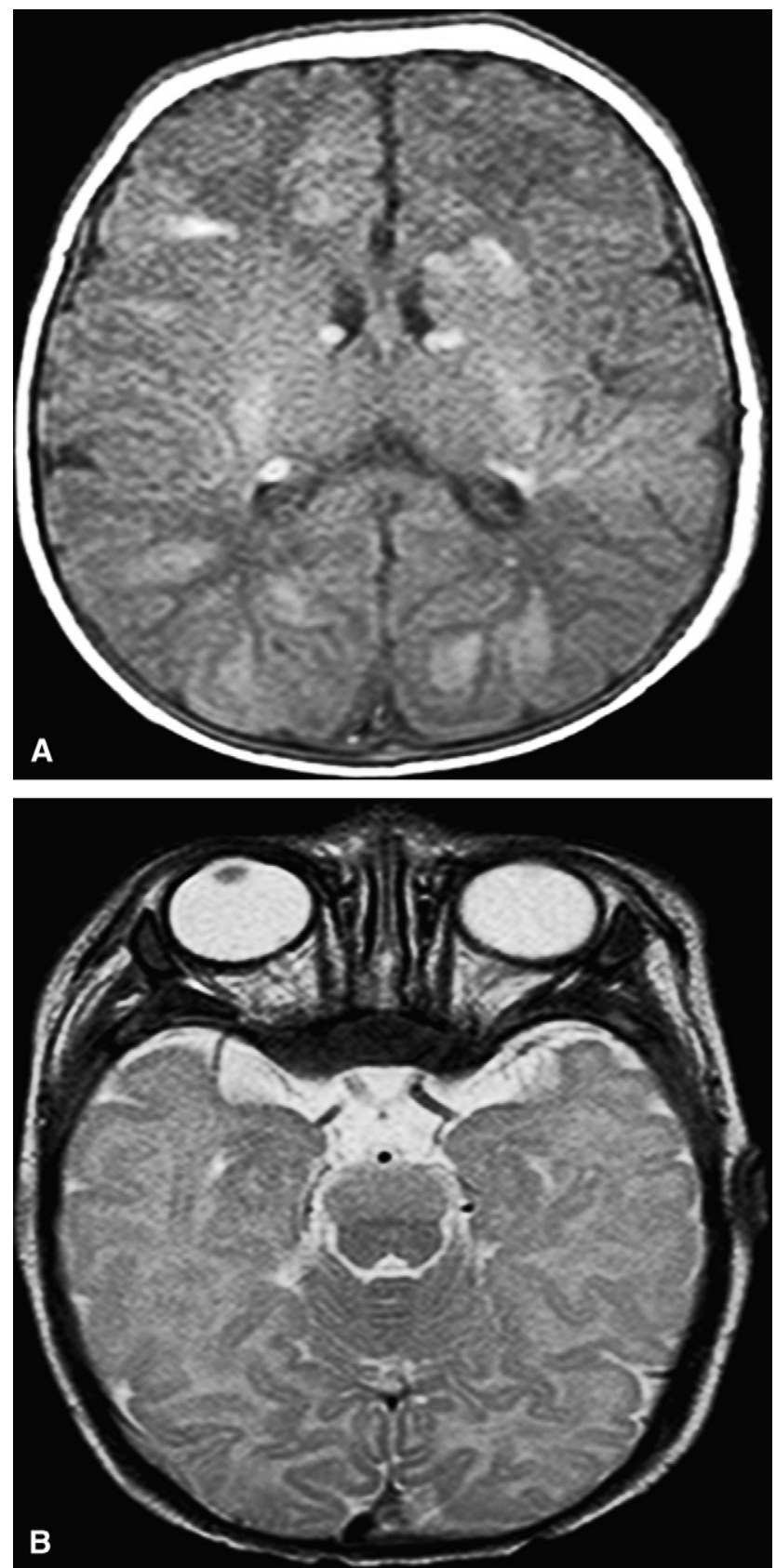

FIGURE 2. Brain magnetic resonance imaging revealed multiple cortical tubers, subependymal nodules, and right intraocular nodule raising suspicion of retinal hamartoma. followed up for 2 months after discharge and is in excellent clinical condition.

\section{DISCUSSION}

Rhabdomyoma has been reported to be the most common type of cardiac tumor in fetuses and children. Multiple cardiac rhabdomyomas on fetal echocardiography almost certainly signify an association with tuberous sclerosis, as in this case. Depending on the size and location, clinical manifestations of cardiac rhabdomyoma could be similar to those of congenital cardiac defects. Genuine association of cardiac rhabdomyomas with congenital heart anomalies is rare. ${ }^{1,2}$ Because rhabdomyomas tend to regress spontaneously during the first 2 to 4 years after birth, it is the severity of the congenital heart disease that determines the prognosis. Conservative management for the congenital heart defects until complete regression of the tumor has occurred, if possible, thus seems sensible. Significant ventricular inflow or outflow obstruction associated with hemodynamic instability, however, may require early surgical resection of the tumor. ${ }^{3,4}$ In this case, it was deemed that systemic perfusion was maintained by right ventricular ejection and nonrestrictive interatrial communication, even though the LV mass itself may have caused LV inflow and outflow obstruction. Because huge masses in the LV precluded us from performing early primary repair of TOF, we elected to perform a systemic-pulmonary shunt to defer definitive surgery. We speculate that attempts to perform primary repair of TOF in conjunction with tumor debulking might have resulted in incomplete resection of the tumor, conduction tissue injury, and postoperative LV dysfunction.

\section{References}

1. Russell GA, Dhasmana JP, Berry PJ, Gilbert-Barness EF. Coexistent cardiac tumors and malformations of the heart. Int J Cardiol. 1989;22:89-98.

2. Jiang ZY, Pirvoca A, Sekarski N, Hack I, Laurini R, Janzer R, et al. Transposition of the great arteries, pulmonary atresia, and multiple ventricular septal defects associated with multiple cardiac rhabdomyomas in a case of tuberous sclerosis. Pediatr Cardiol. 2000;21:165-9.

3. Llina MV, Jaeggi ET, Lee KJ. Neonatal rhabdomyoma causing right ventricular inflow obstruction with duct-dependent pulmonary blood flow: successful stenting of PDA. Catheter Cardiovasc Interv. 2007;69:881-5.

4. Ono M, Boething D, Akin E, Goerler H, Breymann T. Coexistent cardiac rhabdomyoma with mitral valve anomaly in patients with tuberous sclerosis: a case report. Thorac Cardiovasc Surg. 2007;55:120-1. 